\title{
DOI: 10.12731/2658-4034-2021-12-6-60-77 УДК 373.1
}

\section{ВОЗМОЖНОСТИ ВЛИЯНИЯ НА СОЦИАЛЬНЫЕ УСТАНОВКИ В ЦИФРОВОЙ ОБРАЗОВАТЕЛЬНОЙ СРЕДЕ ШКОЛЫ}

\author{
Ванина Э.В., Петрова Е.Г., Бякова Е.В.
}

Актуальность темы исследования. Выбор темы обусловлен тем, что на сегодняшний день недостаточно изучены возможности и эффекты целевого влияния циирровых инструментов на сочииальные установки обучающихся.

Проблема исследования. Ключевой для исследования стала проблема конструирования позитивного педагогического влияния на сочиальные установки обучающихся через циифровую среду.

Цель исследования. Теоретически обосновать обобщенную модель содержания сочиильной установки, проанализировать способы влияния на сочиальные установки (в частности на примере социальной установки, направленной на безопасное поведение в сети Интернет) педагогическими средствами, включенныли в школьную циифровую образовательную среду и выявить результативность имеющихся в практике школы инструментов влияния на сочиальные установки.

Методы исследования. В ходе исследования были использовань следующие научные методы: теоретический анализ, моделирование, эксперимент.

Результаты исследования. В результате моделирования стало возможным на примере социальной установки к объекту "Безопасность в сети Интернет» создать и в пилотном режиме экспериментально проверить технологию конструирования педагогического влияния на социильные установки обучающихся. Ключевыми этапами технологии стали создание теоретической модели, отбор содержания и форм взаимодействия участников образовательного проиесса в ичифровой среде, создание иелевого педагогического инструмента - сетевого квеста. 
Выводы исследования. Эксперимент дал возможность сделать вывод о том, что предлагаемая трехкомпонентная модель сочиальной установки носит универсальный характер и может быть использована при разработке содержания и выборе способов взаимодействия участников образовательного прочесса в циировой среде с учетом влияния на социальные установки обучающихся.

Ключевые слова: сочиальная установка; ичировая безопасность; ичирровая образовательная среда школь; сетевое взаимодействие; сочиальное взаимодействие

\section{OPPORTUNITIES TO INFLUENCE SOCIAL ATTITUDES IN THE SCHOOL DIGITAL EDUCATIONAL ENVIRONMENT}

\section{Vanina E.V., Petrova E.G., Byakova E.V.}

Relevance of the topic under study. The choice of the topic is due to the fact that to date, the possibilities and effects of the targeted influence of digital tools on the social attitudes of students have not been sufficiently studied.

Research problem. The key issue for the study was the way to construct the positive pedagogical influence on the social attitudes of students through the digital environment.

The aim of the study is to theoretically substantiate a generalized model of the content of a social attitude, analyze ways of influencing social attitudes (in particular, using the example of the social attitude aimed at safe behavior on the Internet) by pedagogical means included in the school digital educational environment and identify the effectiveness of the tools available in school practice for influencing social installation.

Research methods. In the course of the research, the following methods were used: theoretical analysis, modeling, experiment.

Research results. As a result of modeling, it became possible, using the example of the social attitude to the object "Security on the Internet", to create and in a pilot mode experimentally test the technology 
of constructing pedagogical influence from the creation of a theoretical model, through filling it with specific content and creating the pedagogical tool-a network quest.

Conclusions of the study. The experiment made it possible to conclude that the proposed three-component model of social attitude is universal and can be used in the development of the content and the choice of methods of interaction between participants in the educational process in the digital environment, taking into account the impact on the social attitudes of students.

Keywords: social attitude; digital security; school digital educational environment; network interaction; social interaction

\section{Введение}

За последние два десятилетия с развитием технологий жизнь современного человека существенно изменилась. Большинство социальных взаимодействий на сегодняшний день перенесены в цифровую среду, которая представляет нам набор цифровых технологий и ресурсов для самореализации, личностно-профессионального развития, решения различных бытовых и профессиональных задач» [4, с. 69-70].

В связи с этим школьное образование не могло не подвергнуться трансформации. Создание школьной цифровой образовательной среды стало новым этапом всего образования в целом, а вынужденный переход на дистанционное обучение во время пандемии 2020 г. ускорил эту деятельность.

Важным этапом в развитии педагогической мысли стало педагогическое осмысление понятий, вошедших в научный словарь с внедрением цифровых технологий, и, в частности, понятия «цифровая образовательная среда», которое не является на сегодняшний день общепринятым и устоявшимся. В своей работе мы руководствовались педагогическим подходом к определению цифровой среды, описанным О.Н. Шиловой: «Опосредованный использованием цифровых технологий и цифровых образовательных ресурсов комплекс отношений в образовательной деятельности, способствующих реа- 
лизации субъектами образовательного процесса возможностей по освоению культуры, способов самореализации, выстраивания социальных отношений, нацеленных на формирование ответственного цифрового поведения гражданина современного общества» [10, с. 8].

Цифровая трансформация является предметом активных научных исследований, в ходе которых рассматриваются различные аспекты влияния цифровых технологий на школьников [5, с. 13]. Однако, приоритетно цифровые технологии, и, в частности, Интернет, рассматриваются в негативном контексте. Например, С. Ливингстон и П.К. в своей работе сосредотачиваются на изучении и управлении агрессивными рисками в цифровую эпоху, с которыми сталкиваются подростки [13, p. 639]. М. Аппель, Б. Штигльбауэр и др. рассматривают в своей работе поведение человека и, в частности, вербальную агрессию в цифровой среде [11, p. 236]. Ключевым субъектом исследований в большинстве случаев является подросток [15, р. 408], а родители рассматриваются как контролирующий субъект [9, с. 39]. Наиболее разносторонне были проанализированы возможности взаимовлияния субъектов образовательного процесса в работе [14, р. 1112].

В то же время, на наш взгляд, остается мало анализируемым позитивный эффект цифровой образовательной среды для социализации и развития обучающихся, формирования адекватных социальных установок по отношению к ключевым объектам: безопасности, коммуникации и другим. Педагоги понимают важность и необходимость внедрения цифровых технологий в образовательный процесс, но вместе с тем еще не в полной мере владеют всеми необходимыми цифровыми инструментами, и понимают их многофункциональность с точки зрения развития и формирования определенных установок у школьников. И здесь необходимо учитывать взаимовлияние цифровой среды на человека и человека на цифровую среду. С одной стороны, поведение человека в цифровой среде во многом определяется теми социальными установками, которыми он руководствуется и в обычной жизни, в то же время и сама цифровая среда становится инструментом влияния на определенные социальные установки обучающихся. 
Интерес к формированию социальных установок у обучающихся не случаен. В классических и современных работах отечественных психологов показано, что особенности социальной ситуации развития - сущностной характеристики возрастного этапа развития, введенной Л.С. Выготским, - решающим образом определяют направление, содержание и характер возрастного развития ребенка, ожидания и требования, предъявляемые к нему, его место в системе социальных отношений [3, с. 226]. Решение специфических задач, которые ставит ребенку вовлекающая его цифровая среда, оказывает влияние на содержание его развития, а именно приобретаемые ребенком новые психические свойства и качества, а также социальные установки, т.е. благоприятные или неблагоприятные оценочные реакции на что-либо или на кого-либо, которые выражаются во мнениях, чувствах или целенаправленном поведении по отношению к объекту установки. [6, с. 81].

По мнению Г.В. Солдатовой, «учителя включаются не только не очень активно, но и недостаточно рано в цифровую социализацию детей. На наш взгляд, расширение репертуара и интенсификация применения стратегий учительской медиации может быть обеспечена повышением цифровой компетентности учителей и изменением установок по отношению к своей роли в процессе цифровой социализации и к цифровой среде как источнику не только новых рисков для подрастающего поколения, но и новых возможностей» [8, с. 381].

В связи с этим задача выявления педагогического потенциала, обеспечивающего влияние цифровой среды на социальные установки обучающихся, становится особо актуальной. В статье представлены результаты опытно-экспериментальной работы по изучению и использованию в практике педагогических инструментов влияния школьной цифровой среды на социальные установки обучающихся.

Одной из востребованных на сегодняшний день социальных установок, является социальная установка, направленная на безопасное поведение в сети Интернет. Одновременно с развитием цифровой грамотности и формированием компетенций для цифровой деятель- 
ности на первый план выходят вопросы обеспечения информационной безопасности, характеризующейся достижением состояния защищенности личности от внутренних и внешних информационных угроз, а также подразумевающей сочетание инструментов и навыков, которые пользователи могут применять во избежание контроля над их действиями в сети Интернет, доступа или вмешательства в их цифровую информацию и электронные устройства и программы.

\section{Цель работы}

Теоретически обосновать обобщенную модель содержания социальной установки, проанализировать способы влияния на социальные установки (в частности на примере социальной установки, направленной на безопасное поведение в сети Интернет) педагогическими средствами, включенными в школьную цифровую образовательную среду и выявить результативность имеющихся в практике школы инструментов влияния на социальные установки.

\section{Материалы и методы}

Теоретический анализ литературы дал возможность смоделировать содержание социальной установки в общем виде. Основанием для построения модели послужили исследования М. Смита $[6$, с. 202], который выделил следующие компоненты социальных установок: когнитивный, включающий в себя знания человека об объекте, к которому относится его социальная установка; аффективный, к которому относятся эмоции, переживаемые человеком в отношении данного объекта; поведенческий (конативный), включающий в себя реальные и потенциальные действия человека, которые он непосредственно совершает или готов совершить по отношению к соответствующему объекту, целенаправленно анализируя, регламентируя, дозируя и отбирая факторы, которые оказывают существенное влияние на формирование и изменение социальных установок обучающихся. К таким факторам относятся: источник информации; содержание и порядок поступления информации; учет особенностей аудитории. 
Несмотря на то, что существует еще несколько подходов к пониманию термина «социальная установка», мы увидели следующие преимущества в модели по Смиту. Трехкомпонентная модель позволяет увидеть возможности педагогического воздействия на социальную установку: через увеличение и систематизацию объема знаний об объекте социальной установки, через проживание определенных ситуаций, связанных с объектом установки и накопление различного (и позитивного, и негативного) опыта относительно установки в учебных (специально смоделированных) условиях.

Для экспериментального исследования была выбрана социальная установка, связанная с цифровой безопасностью обучающихся.

Рассмотрим более подробно возможности формирования и развития социальной установки на цифровую безопасность через использование возможностей цифровой образовательной среды и выбранных современных психолого-педагогических подходов.

В толковом словаре С.И. Ожегова понятие безопасность трактуется как «состояние, при котором не угрожает опасность, есть защита от опасности» [7, с. 907 ]. Таким образом, понятие «безопасность» характеризует ситуацию, в которой человек защищен от различных опасностей (политических, экономических, информационных, психологических и т.д.) и владеет способами защиты от них. В условиях повсеместной информатизации общества особую актуальность приобретает обеспечение цифровой безопасности как на уровне государства, так и на уровне гражданина. Наиболее уязвимым контингентом пользователей информационных сетей при этом являются дети. Во многом это связано с участившимися случаями интернет-мошенничества, оказания психологического давления на подростков, вовлечения их в совершение преступлений.

Установка на цифровую безопасность предполагает осознание цифровых угроз, а также готовность к ответственному и безопасному поведению в сети для продуктивного интернет-взаимодействия $[12$, p. 841]. При этом каждый компонент установки имеет собственное содержательное наполнение: 
Когнитивный колпонент: знание правил безопасного поведения (в том числе в сети Интернет), осознание необходимости их соблюдения.

Аффективный компонент: привлекательность защищенности, наличие устойчивой предпочтительности определенного образа действия в вопросах безопасного поведения в сети.

Конативный компонент: опыт безопасного поведения и готовность применять навыки (компетентность) безопасного поведения в новых условиях и ситуациях.

На формирование и развитие у обучающихся установки на цифровую безопасность будут оказывать влияние следующие особенности обучающихся, обусловленные возрастом:

- 5-6 классы. Наблюдается несогласованность убеждений, нравственных идей и понятий с поступками, действиями и поведением; происходит разбалансировка процессов возбуждения и торможения.

- 7-9 классы. Социальные нормы поведения, установленные взрослыми, отходят на второй план; сложные, отношения с педагогами и/или одноклассниками, в результате нежелания подростка подчиняться их требованиям и заданиям.

- 10-11 классы. Установление психологической независимости во всех сферах: в моральных суждениях, политических взглядах, поступках; ранимость уживается с поразительной черствостью, болезненная застенчивость - с развязностью, желание быть признанным и оцененным другими - с подчеркнутой независимостью, борьба с авторитетами - с обожествлением случайных кумиров; вмешательство в личные дела извне для них невыносимо, тем более - принуждение.

Теоретический анализ позволил описать в обобщенном виде психолого-педагогические возможности цифровой образовательной среды образовательного учреждения (далее - ЦОС ОУ) для влияния на социальную установку. Психолого-педагогические возможности использования школьной ЦОС для влияния на социальную установку учащихся, объектом которой является цифровая безопасность, представлены в Таблице 1. 
Таблица 1.

Психолого-педагогические возможности использования ЦОС для влияния на социальную установку (объект социальной установки - безопасность)

\begin{tabular}{|c|c|c|c|}
\hline $\begin{array}{c}\text { Особенности } \\
\text { ЦОС, влияющие } \\
\text { на формирование } \\
\text { социальной } \\
\text { установки }\end{array}$ & \multicolumn{3}{|c|}{$\begin{array}{l}\text { Объект социальной установки: } \\
\text { БЕЗОПАСНОСТЬ цифровая }\end{array}$} \\
\hline $\begin{array}{c}\text { Формы } \\
\text { взаимодействия }\end{array}$ & \multicolumn{3}{|c|}{$\begin{array}{c}\text { Учебные сетевые взаимодействия, коммуникации в } \\
\text { цифровой образовательной среде }\end{array}$} \\
\hline Содержание & \multicolumn{3}{|c|}{$\begin{array}{l}\text { Задания направленные: } \\
\text { • на осознание наличия в Интернете негативной, вредной } \\
\text { и опасной информации; } \\
\text { • на изучение способов представления себя в Интернете, } \\
\text { правил личной безопасности в сети; } \\
\text { • на осознание основных возможностей и рисков, } \\
\text { связанных с удовлетворением потребностей } \\
\text { (коммуникативных, познавательных, в товарах и услугах } \\
\text { и т.д.) с помощью различных онлайн технологий; } \\
\text { • на приобретение опыта безопасной работы с сети Интернет }\end{array}$} \\
\hline $\begin{array}{l}\text { Организация } \\
\text { деятельности }\end{array}$ & $\begin{array}{l}5-6 \text { класс } \\
\text { Участие в } \\
\text { учебных сетевых } \\
\text { взаимодействиях } \\
\text { (учебных сетевых } \\
\text { проектах) под } \\
\text { руководством } \\
\text { учителя } \\
\text { прежде всего } \\
\text { цифровой среде } \\
\text { образовательного } \\
\text { учреждения }\end{array}$ & $\begin{array}{l}7-9 \text { класс } \\
\text { Участие в } \\
\text { учебных сетевых } \\
\text { взаимодействиях } \\
\text { (учебных сетевых } \\
\text { проектах) } \\
\text { совместно с } \\
\text { учителем в } \\
\text { том числе на } \\
\text { сторонних } \\
\text { образовательных } \\
\text { порталах }\end{array}$ & $\begin{array}{l}\text { 10-11 класс } \\
\text { Самостоятельное } \\
\text { участие в } \\
\text { учебных сетевых } \\
\text { взаимодействиях } \\
\text { (учебных } \\
\text { сетевых } \\
\text { проектах) в } \\
\text { том числе на } \\
\text { сторонних } \\
\text { образовательных } \\
\text { порталах }\end{array}$ \\
\hline
\end{tabular}

Следующим методом, использованным при экспериментальной работе, стал SWOT-анализ, который позволил системно оценить возможности и проблемы в ЦОС с точки зрения влияния на социальные установки обучающихся.

Среди сильных сторон были отмечены:

- сформированные в образовательном учреждении условия для практического применения онлайн-инструментов в реализации программы по формированию безопасного поведения в сети Интернет; 
- опыт педагогов по созданию электронных образовательных ресурсов, организации проектной деятельности на основе использования онлайн-сервисов и онлайн-инструментов;

- сформированная инфраструктура цифровой среды, имеющая в составе школьную локальную сеть с выделенным сервером и системой электронного документооборота;

- учебные и административные кабинеты, в том числе и три стационарных и три мобильных компьютерных класса, оборудованные компьютерной техникой с доступом в сеть Интернет;

- школьный информационно-образовательный портал, разработанный школьный ресурс «МОДЭЛь 3L» Мотивация, Обучение, Действие через ЭЛектронные ресурсы для 3L (life-long learning - обучения длиною в жизнь);

- библиотека, подключенная к Национальной электронной библиотеке (НЭБ).

Среди проблем были обозначены:

- уязвимость обучающихся перед опасностями сети Интернет вследствие прямой зависимости между уровнем активности в цифровой среде и степенью возможных рисков и угроз;

- недостаточная компетентность педагогов в вопросах цифровой безопасности и методике формирования безопасного поведения обучающихся в сети Интернет.

Анализ позволил выявить оптимальный путь развития механизмов влияния на социальные установки - через школьный ресурс «МОДЭЛь 3L» и сетевые события.

В ходе работы был использован и эксперимент, целью которого стала проверка результативности влияния ЦОС на социальную установку относительно объекта «Безопасность в сети Интернет».

Для развития навыков безопасного поведения в сети Интернет было разработано несколько цифровых событий, в том числе сетевой квест «Гарри Поттер и Дары Интернета» по мотивам литературных произведений Дж. Роулинг. Подойти к обучению через персонажа книги - традиционный педагогический прием, ведь так 
до учащихся доносится информация через любимую, понятную и доступную возрасту форму в литературном формате. С течением времени меняются пристрастия детей, появляются новые кумиры, поэтому для привлекательности был выбран один из самых популярных героев современных школьников - Гарри Поттер, мальчик с непростой судьбой, обладающий магическими способностями, но не лишённый человеческих слабостей. В конце своих приключений он сталкивается с волшебными Дарами, которые существенно облегчают жизнь, но могут также и быть использованы с разрушительной, деструктивной целью. Проведя аналогию с Интернетом и рассматривая его не только как средство связи и быстрого поиска нужной информации, но и как источник определённой опасности, квест, основываясь на содержании книги и одноименного фильма, преподносит детям простые правила сетевой безопасности в игровой и доступной форме. Целевой аудиторией являются учащиеся 12-14 лет, имеющие компьютерное оборудование с выходом в Интернет и знакомые с книгой или фильмом о Гарри Поттере. Структура квеста состоит из 6 разделов, в каждом из которых заключены задания, влияющие на компоненты социальной установки [1, с. 80-82].

Содержание и форма заданий в квесте соотносятся с компонентами социальной установки следующим образом:

Когнитивный компонент - знание правил безопасного цифрового поведения, осознание необходимости их соблюдения.

Аффективный компонент - привлекательность защищенности, наличие устойчивой предпочтительности определенного образа действия в вопросах безопасного поведения в сети.

Поведенческий компонент - опыт безопасного цифрового поведения и готовность применять навыки (компетентность) безопасного поведения в новых условиях и ситуациях [2, с. 70].

\section{Результаты}

В ходе пилотного эксперимента была создана обобщенная теоретическая модель содержания социальной установки, ее непосредственное наполнение для объекта «Безопасность в Интернет», 
разработан и апробирован инструмент влияния - квест «Гарри Поттер и дары Интернета». Обобщенная модель содержания позволяет конструировать содержание практически любого объекта социальной установки и отбирать наиболее адекватные механизмы влияния.

Для определения уровня сформированности социальных установок у обучающихся в ОУ был создан цифровой ресурс сбора и автоматической обработки данных “Мониторинг цифровой образовательной среды”. Он позволяет в автоматическом режиме обработать данные, полученные в результате диагностики степени сформированности социальных установок обучающихся и определить влияние школьной ЦОС на развитие социальных установок обучающихся.

Анкета состоит из вопросов, направленных на оценку влияния цифровой среды на социальные установки к нескольким объектам, в том числе и сетевой безопасности. Каждый из вопросов был представлен в виде утверждения, связанного с оценкой одного из трёх компонентов социальной установки: когнитивный, аффективный, конативный. По каждому из утверждений учащийся выражал степень своего согласия по шкале от 1 до 10, где 1 - полностью не согласен, а 10 - совершенно согласен. Первое анкетирование проводилось в марте 2021 г. среди учащихся 7 и 9 классов, второе - после включения учащихся в педагогическое взаимодействие через ЦОС в ноябре 2021 г. среди тех же учащихся 8 и 10 классов. Всего в анкетировании приняли участие 98 человек. Данные анкетирования представлены в Таблице 2.

Таблиц̧а 2.

Результаты анкетирования учащихся школы

\begin{tabular}{|c|c|c|c|}
\hline \multicolumn{4}{|c|}{ Март 2021 учебного года } \\
\hline 7 «» & 7 «Б» & 9 «А & 9 «Б» \\
\hline 0,56 & 0,49 & 0,58 & 0,61 \\
\hline \multicolumn{4}{|c|}{ Ноябрь 2021 учебного года } \\
\hline 8 «» & 8 «Б» & 10 «» & 10 «Б» \\
\hline 0,62 & 0,65 & 0,66 & 0,74 \\
\hline
\end{tabular}

На основании двух срезов с незначительным временным интервалом еще рано говорить о том, что имеется положительная ди- 
намика, однако возможно сделать вывод о том, что при целевом педагогическом воздействии на социальные установки есть изменения на уровне классов.

\section{Выводы и область применения результатов}

Формирование социальных установок - очень длительный и сложный процесс. При грамотной организации образовательного процесса в цифровой среде школы можно влиять на социальные установки обучающихся через когнитивный, конативный и аффективный компоненты установок. Экспериментальная проверка показала, что даже за полгода при систематическом воздействии социальная установка школьника может измениться.

Полученные в ходе проведения исследования результаты могут быть использованы:

- руководителями образовательных учреждений при формировании школьной цифровой среды, реализации программы воспитания, т.к. одним из ее результатов становится система ценностей обучающегося, в том числе и набор социальных установок, с которыми выпускник выходит в дальнейшую жизнь;

- исследователями в области образования (педагогами и психологами) для уточнения возможностей и ограничений влияния на социальные установки.

Трехкомпонентная модель социальной установки позволяет конструировать педагогические воздействия в формате игр, сетевых событий и пр., которые будут влиять на социальную установку. Она может быть использована практически для любого объекта социальной установки.

\section{Список литературы}

1. Бякова Е.В. Волшебные свойства школьных сетевых взаимодействий или при чем здесь Гарри Поттер? // Поиск. 2021. № 1. С. 80-82.

2. Ванина Э.В., Бякова Е.В. Применение коммуникативной стратегии диалога для формирования социальных установок у обучающихся 
в цифровой образовательной среде // Актуальные проблемы педагогики и психологии на современном этапе. Материалы V Международной научно-практической конференции. Волгоград, 2020. C. 68-76.

3. Выготский Л.С. Полное собрание сочинений: в 6 т. Т. 4. Педология подростка: Проблема возраста / Под ред. М.Г. Ярошевского. М.: Педагогика, 1984. С. 224-269.

4. Гордеева С.С. Сущность и структура социальной установки в социологии и социальной психологии // Вестник Пермского университета. Философия. Психология. Социология. 2016. № 3(27). https:// doi.org/10.17072/2078-7898/2016-3-135-140

5. Гэйбл Э. Цифровая трансформация школьного образования. Международный опыт, тренды, глобальные рекомендации /пер. с англ.; под науч. ред. П. А. Сергоманова. М.: НИУ ВШЭ, 2019. 108 с.

6. Дэвис Дж.Э. Американская социология. Перспективы, проблемы, методы. М.: Прогресс, 1972. 392 с.

7. Толковый словарь русского языка: 72500 слов и 7500 фразеологических выражений / С.И. Ожегов, Н.Ю. Шведова; Российская АН, Ин-т рус. яз., Российский фонд культуры. 2-е изд., испр. и доп. М.: Азъ, 1994. 907 c.

8. Солдатова Г.У., Рассказова Е.И. Безопасность подростков в интернете: риски, совладание и родительская медиация // Национальный психологический журнал. 2014. № 3(15). https://doi.org/10.11621/ npj.2014.0305

9. Солдатова Г.У., Чигарькова С.В. Стратегии учительской медиации цифровой активности школьников глазами подростков // Цифровое общество как культурно-исторический контекст развития человека. Сборник научных статей и материалов III международной конференции. Коломна, 2020. С. 379-383.

10. Шилова О.Н. Цифровая образовательная среда: педагогический взгляд // Человек и образование. 2020. № 2(63). С. 36-41.

11. Appel M., Stiglbauer B., Batinic B., \& Holtz P. Internet use and verbal aggression: The moderating role of parents and peers // Computers in human behavior. 2014. Vol. 33. P. 235-241. 
12. George M.J., Odgers C.L. Seven fears and the science of how mobile technologies may be influencing adolescents in the digital age // Perspectives on psychological science. 2015. Vol. 10, No. 6. P. 832-851.

13.Livingstone S., Smith P.K. Annual research review: Harms experienced by child users of online and mobile technologies: The nature, prevalence and management of sexual and aggressive risks in the digital age // Journal of child psychology and psychiatry. 2014. No. 55(6). P. 635-654.

14. Shin W., Lwin M.O. How does "talking about the Internet with others" affect teenagers' experience of online risks? The role of active mediation by parents, peers, and school teachers // New Media \& Society. 2017. Vol. 19, No. 7. P. 1109-1126.

15. Symons K., Ponnet K., Emmery K., Walrave M., Heirman W. Parental knowledge of adolescents' online content and contact risks // Journal of youth and adolescence. 2017. Vol. 46, No. 2. P. 401-416.

\section{References}

1. Byakova E.V. Volshebnyye svoystva shkol'nykh setevykh vzaimodeystviy ili pri chem zdes' Harry Potter? [The magical properties of school network interactions or what does Harry Potter have to do with it?]. Poisk [Search], 2021, no. 1, pp. 80-82.

2. Vanina E.V., Byakova E.V. Primenenie kommunikativnoy strategii dialoga dlya formirovaniya social'nykh ustanovok u obuchayushchikhsya $\mathrm{v}$ tsifrovoy obrazovatel'noy srede [Application of the communicative dialogue strategy for the formation of social attitudes among students in a digital educational environment]. Aktual'nye problemy pedagogiki i psihologii na sovremennom jetape. Materialy V Mezhdunarodnoj nauchno-prakticheskoj konferencii [Actual problems of pedagogy and psychology at the present stage. Materials of the international scientific and practical conference]. Volgograd, 2020, pp. 68-76.

3. Vygotskiy L.S. Polnoe sobranie sochinenij: v 6 t. T. 4. Pedologiya podrostka: Problema vozrasta [The full composition of writings: in 6 volumes. Teenage pedalogy: The problem of age]. Moscow: Pedagogika, 1984, pp. 224-269. 
4. Gordeeva S.S. Sushchnost' i struktura sotsial'noy ustanovki v sotsiologii i sotsial'noy psikhologii [The essence and structure of social attitude in sociology and social psychology]. Vestnik Permskogo universiteta. Filosofija. Psihologija. Sociologija [Perm University Bulletin. Philosophy. Psychology. Sociology], 2016, no. 3 (27). https://doi.org/10.17072/20787898/2016-3-135-140

5. Geibl E. Tsifrovaya transformatsiya shkol'nogo obrazovaniya. Mezhdunarodniy opyt, trendy, global'nyye rekomendatsii [Digital transformation of school education. International experience, trends, global recommendations] / per. s angl.; pod nauch. red. P.A. Sergomanova. Moscow: NIU VSHE, 2019, $108 \mathrm{p}$.

6. Devis Dzh.E. Amerikanskaja sociologija. Perspektivy, problemy, meto$d y$ [American sociology. Perspectives, problems, methods]. Moscow: Progress, 1972, $392 \mathrm{p}$.

7. Tolkovyj slovar' russkogo yazyka: 72500 slov $i 7500$ frazeologicheskih vyrazhenij [Explanatory dictionary of the Russian language: 72500 words and 7500 phraseological expressions]. Moscow: Az, 1994, 907 p.

8. Soldatova G.U., Rasskazova E.I. Bezopasnost' podrostkov v internete: riski, sovladanie i roditel'skaya mediatsiya [Teenagers safety on the Internet: risks, coping and parental mediation]. Nacional'nyj psihologicheskij zhurnal [National psychological journal], 2014, no. 3(15). https:// doi.org/10.11621/npj.2014.0305

9. Soldatova G.U., Chigar'kova S.V. Strategii uchitel'skoy mediatsii tsifrovoy aktivnosti shkol'nikov glazami podrostkov [Strategies for teacher mediation of digital activity of schoolchildren through the eyes of teenagers]. Tsifrovoye obshchestvo kak kul'turno-istoricheskiy kontekst razvitiya cheloveka [Digital society as a cultural and historical context of human development]. Kolomna, 2020, pp. 379-383.

10. Shilova O.N. Cifrovaya obrazovatel'naya sreda: pedagogicheskij vzglyad [Digital educational environment: pedagogical outlook]. Chelovek i obrazovanie [Human and education], 2020, no. 2(63), pp. 36-41.

11. Appel M., Stiglbauer B., Batinic B., \& Holtz P. Internet use and verbal aggression: The moderating role of parents and peers. Computers in human behavior, 2014, vol. 33, pp. 235-241. 
12. George M.J., Odgers C.L. Seven fears and the science of how mobile technologies may be influencing adolescents in the digital age. Perspectives on psychological science, 2015, vol. 10, no. 6, pp. 832-851.

13.Livingstone S., Smith P.K. Annual research review: Harms experienced by child users of online and mobile technologies: The nature, prevalence and management of sexual and aggressive risks in the digital age. Journal of child psychology and psychiatry, 2014, vol. 55, no. 6, pp. 635-654.

14. Shin, W., Lwin, M. O. How does "talking about the Internet with others" affect teenagers' experience of online risks? The role of active mediation by parents, peers, and school teachers. New Media \& Society, 2017, vol. 19, no. 7, pp. 1109-1126.

15. Symons K., Ponnet K., Emmery K., Walrave M., Heirman W. Parental knowledge of adolescents' online content and contact risks. Journal of youth and adolescence, 2017, vol. 46, no. 2, pp. 401-416.

\section{ДАННЫЕ ОБ АВТОРАХ}

Ванина Эмилия Владимировна, к.П.н., доцент кафедры методологии и технологий цифрового образования ГБУ ДПО СПбАППО ул. Ломоносова, 11-13, А, г. Санкт-Петербург, 191002, Россия emiliavanina@gmail.com

\section{Петрова Елена Геннадьевна, директор}

ГБОУ СОШ №551 Кировского района Санкт-Петербурга ул. Танкиста Хрустиикого, 31, г. Санкт-Петербург, 198217, Россия petrovaeg@mail.ru

Бякова Елена Викторовна, учитель, зав. направлением ОЭР ГБОУ СОШ №551 Кировского района Санкт-Петербурга ул. Танкиста Хрустиикого, 31, г. Санкт-Петербург, 198217, Россия elenahistory78@mail.ru 


\section{DATA ABOUT THE AUTHORS}

Emilia V. Vanina, Ph.D., Associate Professor, Department of Methodology and Technologies of Digital Education

St. Petersburg Academy of Postgraduate Pedagogical Education 11-13, A, Lomonosov Str., St. Petersburg, 191002, Russia emiliavanina@gmail.com

\section{Elena G. Petrova, Director}

Secondary School No. 551 of the Kirovsky district of St. Petersburg

31, Tankist Khrustitsky Str., St. Petersburg, 198217, Russia petrovaeg@mail.ru

Elena V. Byakova, Teacher

Secondary School No. 551 of the Kirovsky district of St. Petersburg

31, Tankist Khrustitsky Str., St. Petersburg, 198217, Russia elenahistory78@mail.ru 